\title{
"ERGONOMIZATION" OF THE WORKING ENVIRONMENT AND BUILDING UP OF HEALTHY WORKING POSTURE OF DENTAL STUDENTS
}

\author{
Lydia G. Katrova ${ }^{1}$, Ivan Ivanov², Marin Ivanov ${ }^{2}$, Kalina Pejcheva ${ }^{3}$ \\ 1) Department of Public Dental Health, 2) Students, Faculty of Dental Medicine, \\ 3) Department of Conservative Dentistry, \\ Faculty of Dental Medicine, Medical University - Sofia, Bulgaria
}

\section{SUMMARY}

The purpose was to assess the knowledge of dental students of the ergonomics' principles and how they develop adequate skills to work safe in clinic. Methods: A questionnaire, comprising a set of 25 close-ended questions and 2 open-ended questions to rate the knowledge, attitude and motivation regarding the good posture, training environment and real clinical practice' organization, was distributed among 260 from a total of 685 dental students. Demonstration of proper working posture and training in it had been given to 4-th and 5-th year' students. The process was registered by photos. Data were treated statistically using SPSS. 16.1. Results: Most of students report they know the right working posture $(52,6 \%)$ or "have an idea" $(36,6 \%)$. Almost all of them are persuaded it is important to work in good posture $(95,9 \%)$. They would like to be trained in ergonomics $(96,4 \%)$, and think it should be done before graduation $(90,2 \%)$. Students agree on integrating ergonomic training into the clinical training and think it is possible $(73,6 \%)$. The students originating from "dental" families demonstrated higher interest in ergonomics. The photos taken before the training showed that knowledge without practice is not stable. Conclusion: The students understand the importance of the practical application of the dental ergonomics principles. Registering skills is an important education tool. The findings of the research support the argument for integrating ergonomics in clinical studies.

Key words: dental ergonomics, logistic training, dental education, professional health of dentists.

\section{NECESSITY AND PREREQUISITES}

Many publications are featured in scientific literature that prove that despite technological advance in dental equipment industry, the discomfort and deterioration of the working capacity of the dental practitioners due to locomotory system damage are a daily risk $[1,2,5]$. According to Professor Oene Hokwerda about $65 \%$ of dental practitioners suffer from muscle-skeletaldisorders, varying from discomfort and sporadic pain to functional restrictions and loss of working ability $[3,4]$. Even students report pain and discomfort after having worked $[3,10]$.

The 3-rd year students at the Faculty of Dental Medicine in Sofia are taught - through lectures and seminars on Public Dental Health - the following disciplines which are directily or indirectly related to dental ergonomics:

- basics of dental ergonomics,

- organization of curative and diagnostic process,

- dental team and auxiliary personnel,

- professional risks and prevention of them[10].

Furthermore, up to this moment research has been carried out on the risk factors in the working environment of the students: the impact of allergenic agents, use of personal protective equipment [9], stress-inducing factors amongst students [8] etc.

Another beneficial preconditions for introducing ergonomics to the students' curriculum is the updating of dental equipment in clinical environment. On the other hand, still missing are some basic organizational measures for improving the general conditions for clinical work and education such as: assistance, use of rubber-dam, organization of patients' visits.

Another favorable prerequisite is the research on the needs and advantages of working environment improvement carried out by the Students' Dental Ergonomics' Group [11, $12,13]$. Unfortunately, there is no research evidencing the process of integrating the knowledge acquired during the course in public dental health and its further transformation into a sustainable healthy professional behavior. Methodology of integrating the ergonomic skills into the clinical disciplines studies is still missing.

\section{Students' Dental Ergonomics' Group}

After having assessed the conditions and prerequisites and realized how exceptionally pressing and important the issue is, we formed a Students' Dental Ergonomics' Group (SDEG). It was established with the purpose of assisting students and the management of FDM in rationalizing the working environment and teaching correct working posture 
and organization, with regard to the healthy working stereotypes of the future dental practitioners.

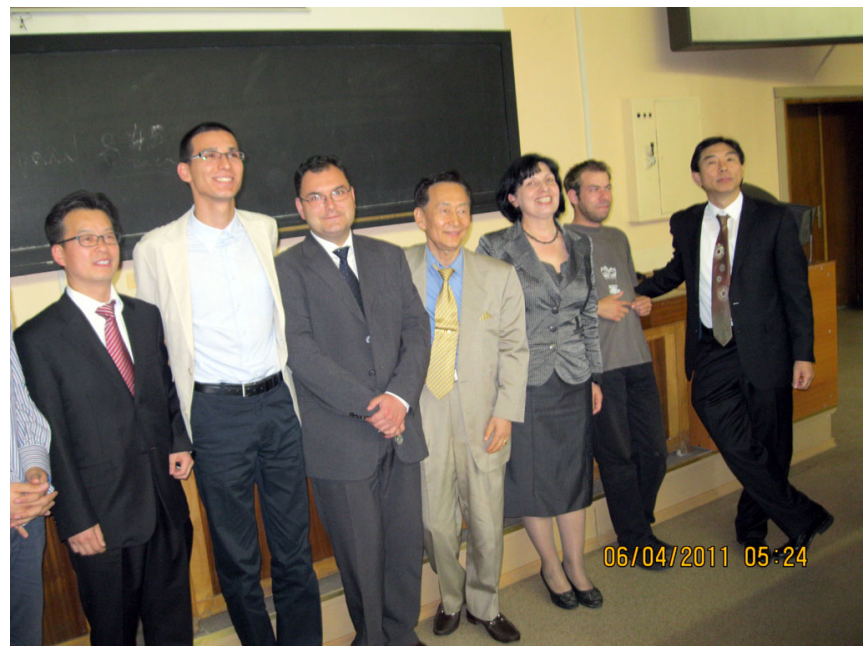

Fig.1. Guest lecturers from South Korea "Proprioceptive Dental Medicine", members and guests

From the very beginning the group got engaged in active international contacts, including the cooperation with European Dental Ergonomy' Society and organization of significant scientific and practical forums (Fig.1).

\section{OBJECTIVES AND TASKS}

The present study is a part of the SDEG's program. The objective of the study is to assess the level of knowledge of the dental students of the principles of ergonomics and how they can apply this knowledge in order to develop relevant skills for healthy professional working posture. The following tasks were formulated for achieving the objective:

1. Survey on the level of knowledge of the 4-th and 5 -th years students;

2. Demonstration of and practical training in for students to acquire ergonomic working posture;

3 . Filming and discussing of the process of acquiring the working posture;

4. Integration of the ergonomic working posture during clinical exercises in conservative dentistry (CD);

5. Comparing the data relevant to the groups of 4 th and 5 th year students.

\section{MATERIAL AND METHOD}

1. A questionnaire consisting of 25 close ended and 2 open ended questions to register knowledge, attitude and motivation of the students related to the correct working posture, the working environment and the actual clinical organization was distributed amongst 260 of a total of 685 dental students. The acquired data was statistically processed with SPSS version 16.1 .

2. With the consent and assistance of the Head of the
Conservative Dentistry Department, during the summer semester of the academic year 2011/2012 a training was carried out in two groups from 4-th year (15 students) and one group of 5-th year (8 students) a total of 23 students. At the first CD seminar a demonstration and practical training was made to the students by Assoc. Prof. Dr. Katrova, ${ }^{1}$ and Marin Ivanov, a 5-th year student ${ }^{2}$, :

- the basic principles of ergonomic posture and work were rehearsed and demonstrated;

- under their supervision each student adjusted his or hers professional chair by him/herself ;

- he/she seated a patient (a volunteering colleague from the group) and performed a clinical exam;

- the progress was registered by photographs.

3. During the following CD exercises each student received individual assistance in correcting his/her posture in accordance with the recommendations before starting to work. During clinical exercises in CD Dr. Pejcheva, Assistant at CD Department supervised the students' work and their ability to keep the ergonomic posture during assignment performance.

\section{Why were these steps necessary?}

The students' skills registered in photos taken before the practical training showed lack of adequacy with the level of knowledge registered by answering the questionnaire. That gave us the reason to perform a practical training and to supervise the students'posture during their clinical work (Fig. 2a\&2b and Fig. 3).
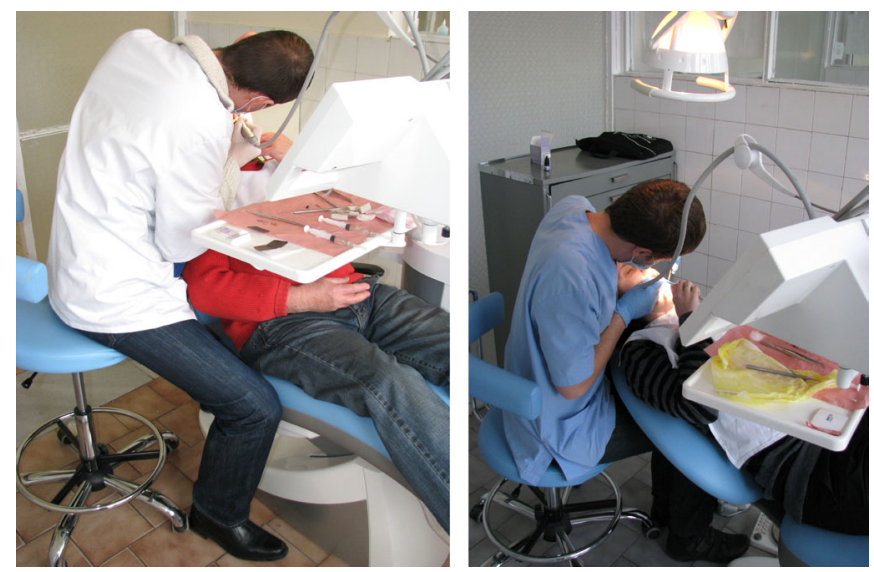

Fig. 2a. and 2b.: A working posture which will rapidly lead to serious damage.

1. Head of GDE

2. Chairman of GDE

3. More information on the ergonomic posture can be found in „Public dental health, dental profession, dental practice”, a textbook for students, specializing and practitioners, L. Katrova, published by WINI 1837, Sofia, 2011,189-225 Sofia, 2011,189-225“. 


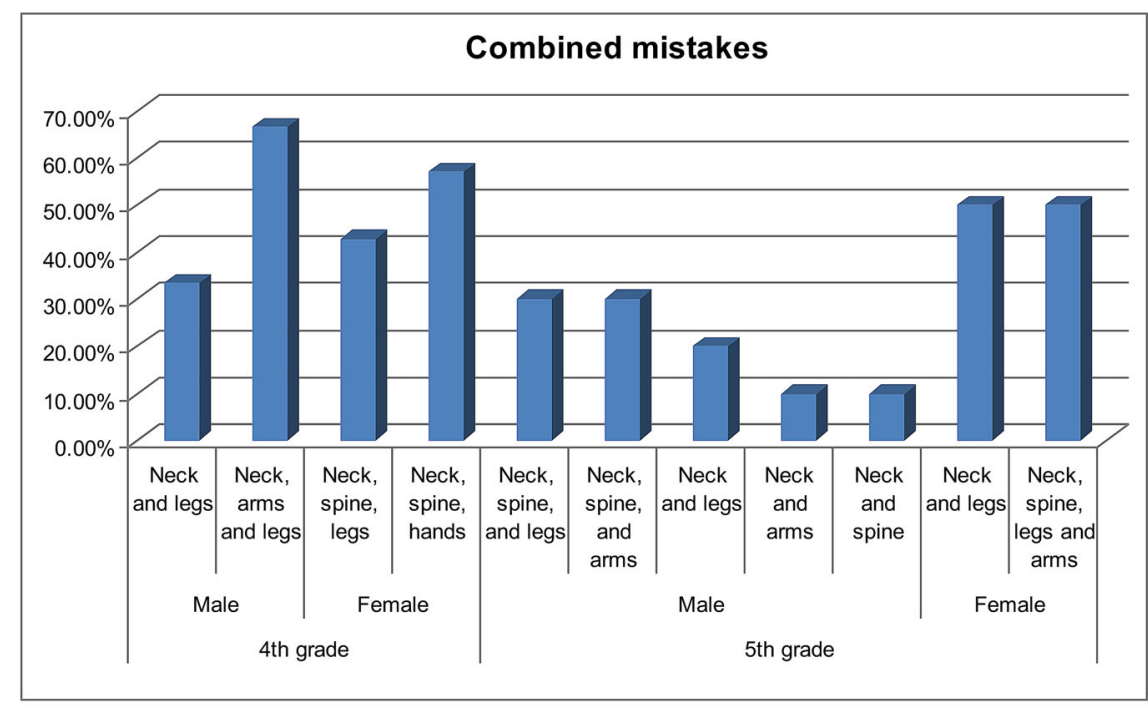

RESULTS

1. Questionnaire results: The response rate (Fig. 2.) was at $74,62 \%$. A number of 194 students with an average age of 22,3 years answered the questionnaire. Male/female ration was at 44,3:55,7. (Fig. 4.).

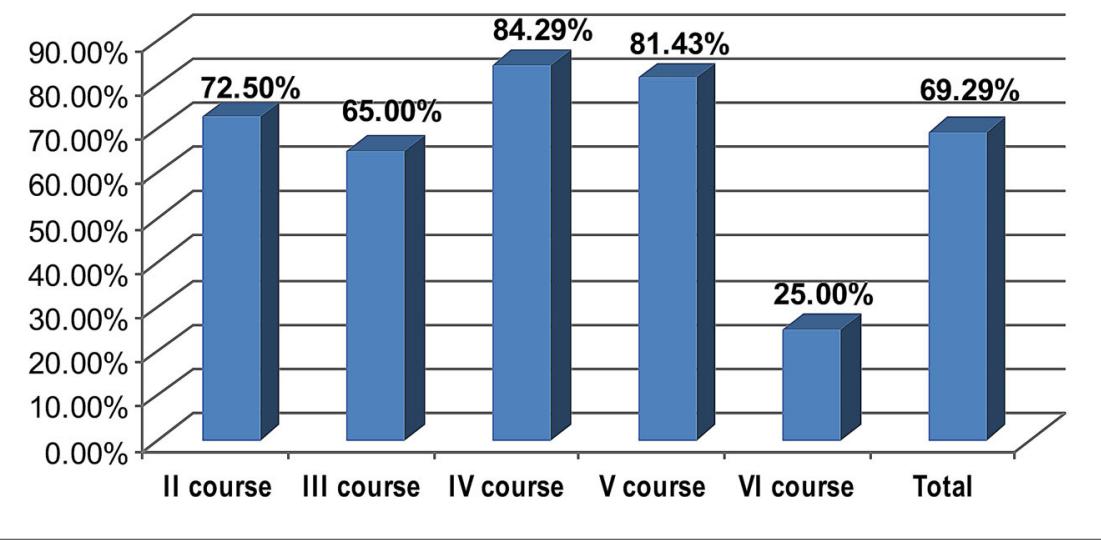

The majority of the students responded that they are familiar with correct working posture $(52,6 \%)$ or that they "have an idea" (36,6\%) (Fig.5).
Fig. 3. Incorrect posture' problems

Fig. 4. Response rate 


\section{Bar Chart}

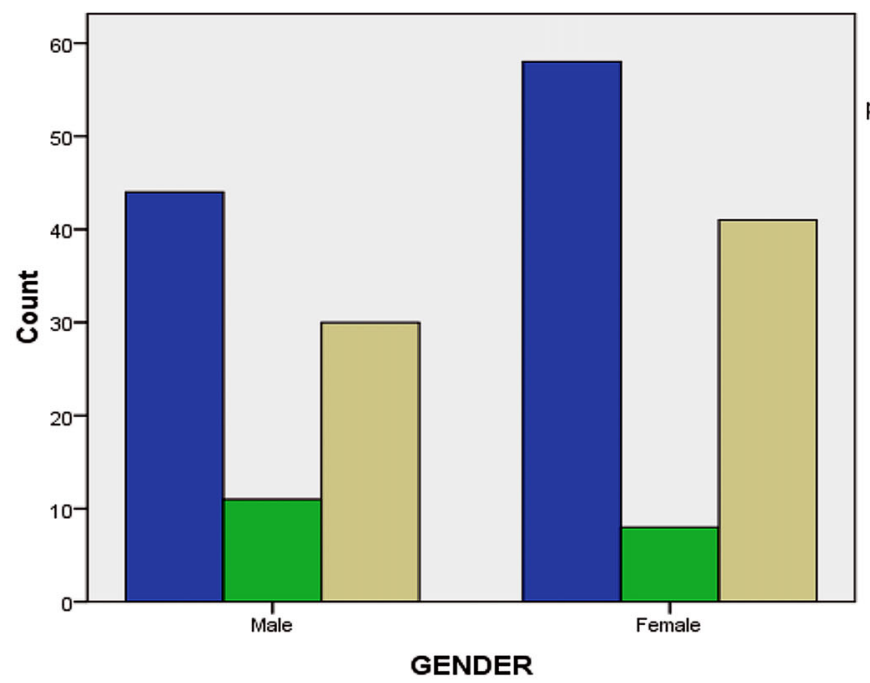

Do you know what is

the correct working

posture of a dental physician at the clinic?

口Yes

$\square$ I have an idea

Almost all are convinced that it is important to keep a good working posture while working $(95,9 \%)$.

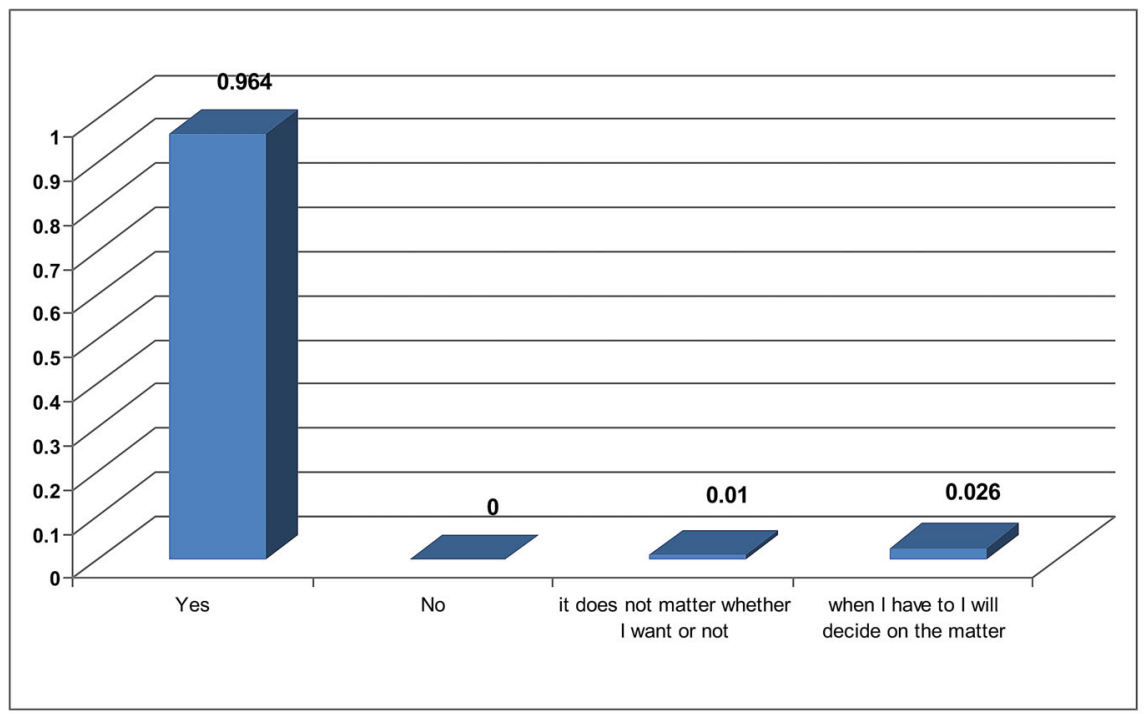

They've acquired knowledge on the subject from: the public dental health course $(34,1 \%)$, their clinical tutors $(27,3 \%)$, practical training $(15,3 \%)$ selfeducation $(16,2 \%)$.

They would like to be trained in dental ergonomics $(96,4 \%)$ and are convinced that this should happen during their academic education (90,2\%). (Fig. 6)
Fig. 5. Do you know what the correct working posture is?
Fig. 6. Do you want to learn and practice the right working posture? 


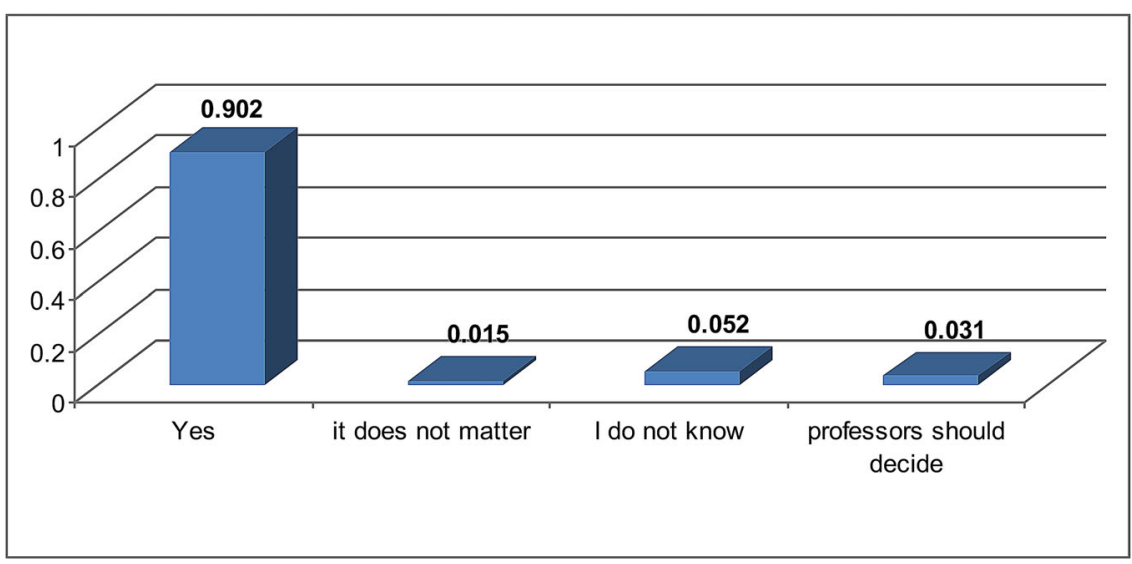

The students unanimously reported that the dental ergonomics training should be integrated in the clinical subjects and that it is possible to do so $(73,6 \%)$ (Fig. 7, Fig. 8).

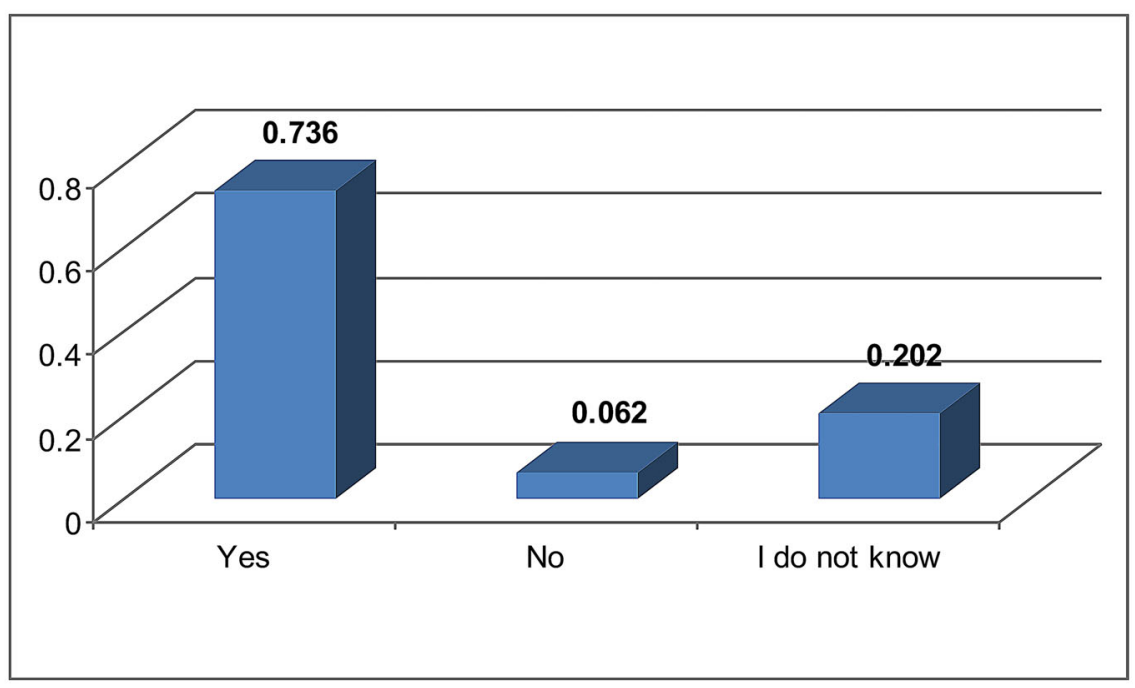

Fig. 8. Is it possible to include ergonomics education in the clinical subjects?
Fig. 7. Do you consider it necessary to be taught in dental ergonomics while you study?

\section{Training results:}

\section{Basic elements of the demonstration}

After discussing the parameters of the correct working posture a symmetrical upright working posture was demonstrated, which took into consideration the individual size from each student ( Fig. 9.). 


\section{Parameters of the correct working postures:}

1. The sitting posture is upright and symmetrical

2. The shoulders hanging down relaxed with the upper arms beside the upper body

3. The forearms have been lightly elevated.

4. The angle between lower and upper legs is approx. 105-110

5. The legs are slightly apart, making an angle of between $30-45^{\circ}$,

6. The position of the back of the patient chair

7. The patient's head is appropriately rotated in 3 directions

8. The light beam of the dental operating light is as parallel as possible to the viewing

9. The sitting location, between 09.00-12.00 o'clock (for left-handed people 03.00-12.00

10. The patient's head is rotated and the sitting location adjusted

11. Instruments held in 3 supporting points

Fig. 9. A moment of the training

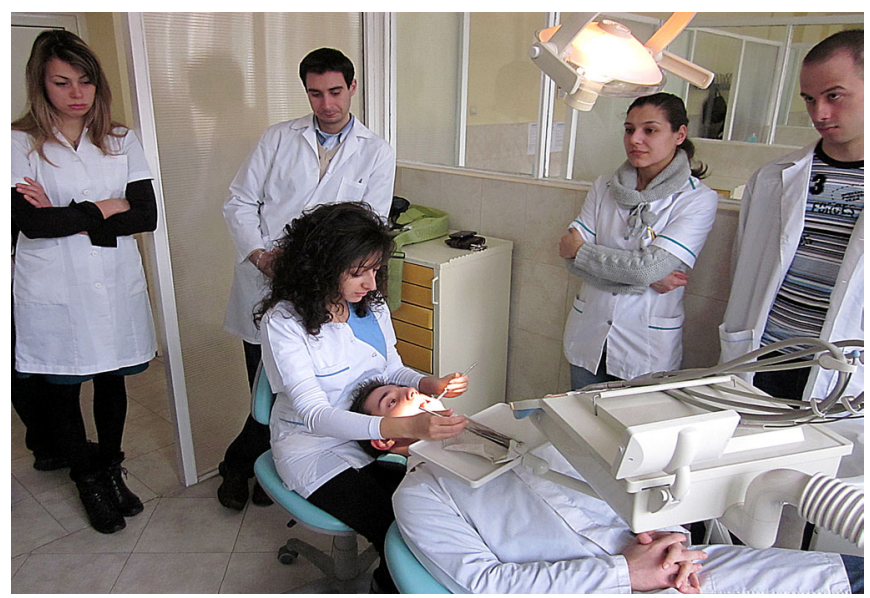

DISCUSSION OF THE RESULTS

1. Questionnaire results discussion:

No significant differences in the answers with respect to gender and year of study (Fig. 8.).

The students who come from dental background exhibit a higher level of interest in ergonomics $(64 \%$ with at least one parent working as a dentist as compared to $36 \%$ of the rest) (fig. 9). Practicing sports also seems to be a predictor for a higher level of interest and knowledge. The knowledge assessment through photographing the abilities to keep working posture during clinical training showed a lower level of knowledge than stated through the questionnaire study (Fig. $10)$.

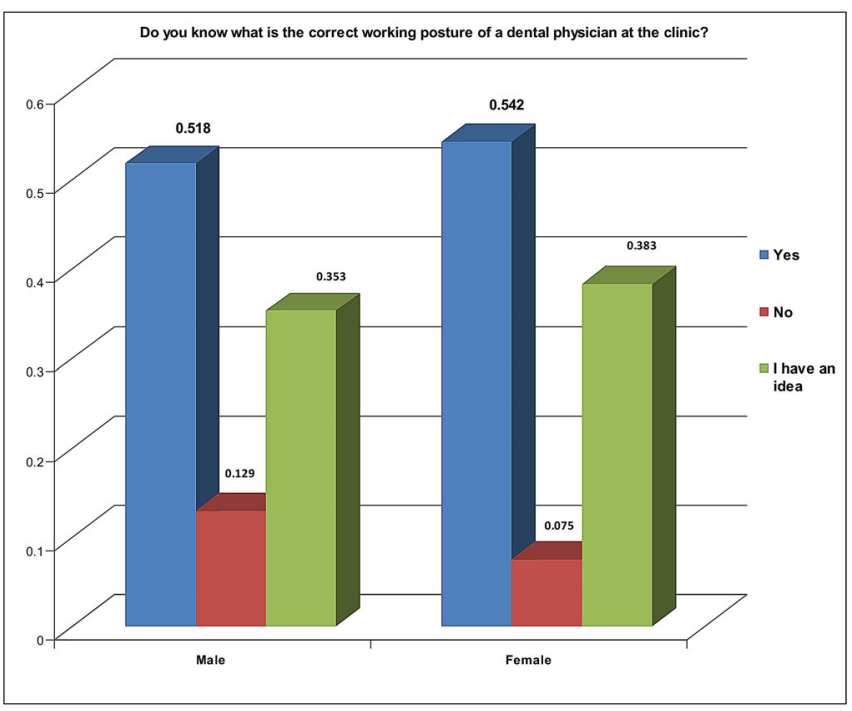

Fig. 10. Gender distribution

Where do you learn about the correct working posture from?

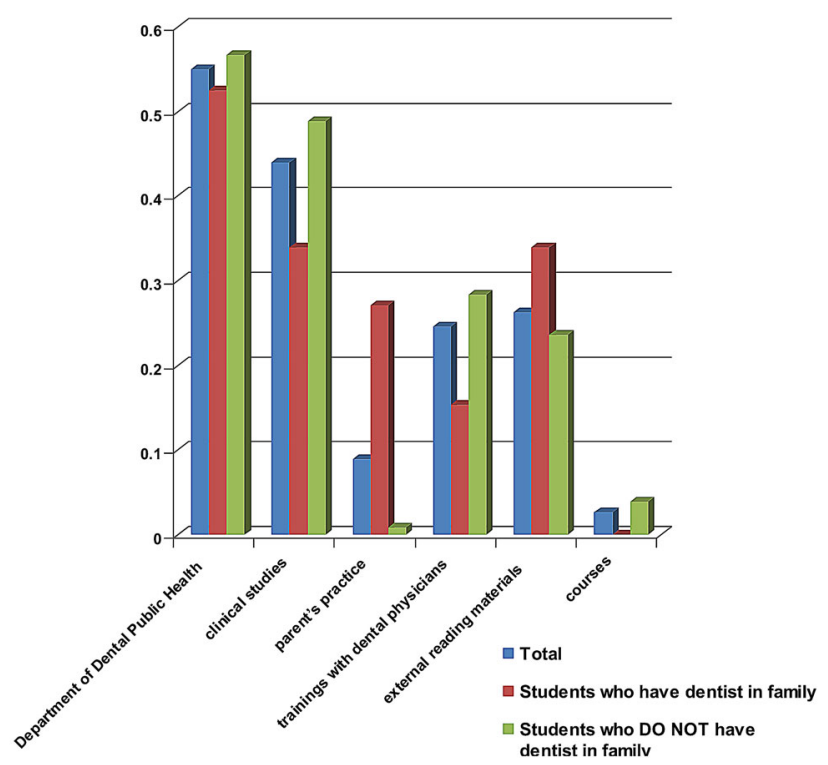

Fig. 11. Predictors for better ground knowledge

\section{Discussion of the students' practical training} results

Our observation showed that all students exhibit interest and desire to acquire knowledge and skills enabling them to work ergonomically. The main difficulties with regard to maintaining ergonomic working posture are due to issues related to the need of working with a dental mirror and the impossibility to provide students with assistance. As it turned out, the upper side teeth are the hardest to access. The posture was correctly maintained usually during treating lower jaw cases. Adjusting the dental chair was the easiest task for students and they felt most confident in achieving it. 
While comparing the students' interest according to their year of study, it turned out that 4-th year students are better motivated. It was them who worked more often in ergonomic posture. All 5-th year students after starting to work seated, while changing the patient's position in order to keep direct visual access to the processed object loose control on the proper working posture. By the middle of the semester under the time pressing to finish more cases students became less and less attentive in ergonomics, and returned to a standing position allowing them "to work faster".

The 4-th year students kept their correct ergonomic posture till the end of the semester. They achieved the norms required by Conservative Dentistry Department. 5-th year students were more successful in using dental mirror, which was expected since they were more experienced with working field orientation. The two 4-th year groups had worked on patients for just a semester and felt insecure. This motivated them to try and achieve a better working comfort.

The factors, demotivating 5-th year students to work ergonomically can be grouped as follows:

1. Established wrong working habits - standing, with a direct view of the working field;

2. Concern generated by the lack of enough time for successfully finishing the assignments allowing them to go for practical examination;

3. Lack of assistance.
The factors, demotivating the CD assistants are mainly coming from the difficulty of assure adequate safety for the patient, especially in endodontic treatments. Students may drop by chance some instruments (nerf-extractors, endofiles, radicular pins or screwing keys), or loose control on hand pieces etc. as they are not usually using rubber-dam and securing rings for endodontic instruments. These factors demonstrate a real danger for an instrument getting into the patient's throat, risking it to be aspirated or swallowed.

\section{be included? \\ At what stage of the education should ergonomics}

The integration of the ergonomic working posture into the dental curriculum should be done as early as mannequin training, as it would be easier for both students and assistants to develop further knowledge and skills.

\section{CONCLUSIONS}

1. The students understand the importance of the practical application of the dental ergonomics principles.

2. Registering skills is an important education tool.

3. The findings of the research support the argument for integrating ergonomics in clinical studies.

\section{Acknowledgments:}

Thanks are expressed to Assoc. Prof. Dr. Radosveta Vasileva, Head department of Conservative Dentistry for her help and encouragement.

\section{REFERENCES:}

1. SmartTec. Musculoskeletal disorders: their symptoms and possible causes. Smartpractice; 2002.

2. Boyd MA, Rucker LM. Effects of Immediate Introduction of Indirect Vision on Performance and Posture. J. Dent. Educ. 1987 Feb;51(2):98-101. [PubMed]

3. Boyd MA. Performance Logic in Clinical Dentistry, Center for Human Performance in Dentitsry. The application of performance logic in Dental Education and Practice The performance simulation laboratory, The University of British Columbia Vancouver, B.C. Canada, 1994.

4. Rucker LM, Sunell S. Ergonomic Risk Factors Associated with Clinical Dentistry. J. Calif. Dent. Assoc. 2002 Feb;30(2):139-148. [PubMed]
5. Sunell, S. and Rucker, L.M. "Ergonomic Risk Factors Associated with Clinical Dental Hygiene Practice", Probe 37(4):159-166, 2003.

6. Nermin Y. Musculoskeletal disorders (MSDs) and dental practice. Part 1. General information, termino$\operatorname{logy}$, aetiology, work-relatedness, magnitude of the problem, and prevention. Int Dent J. 2006 Dec;56(6):359366. [PubMed]

7. Yamalik N. Musculoskeletal disorders (MSDs) and dental practice. Part 2. Risk factors for dentistry, magnitude of the problem, prevention, and dental ergonomics. Int Dent J. $2007 \mathrm{Feb} ; 57$ (1):45-54. [PubMed]

8. Katrova, L. Dental public health, dental profession, dental practice. “WINI 1893” Sofia, 2011. 319 c.
ISBN: 978-954-9437-26-3.

9. Taneva E., Katrova L., Matanova E. Dental students experience with personal protective equipment: knowledge, attitudes and practice. 14th International Dentistry Scientific Congress, 31st May-3rd June 2007, Ohrid, Macedonia

10. Katrova L., Taneva E., Ivanova K., Galabov L. Occupational hazards in Dentistry: Perceived sources of stress among Bulgarian Dental Students. 5th International Congress of Medical Sciences for students and young doctors, 11-14 May 2006, Tribuna Medica, p. 174- http:// www.icmsbg.org/, Sofia, Bulgaria

11. Katrova, M. Marinov, I. Ivanov, Maik Shoaib Assessment of dental students' knowledge on the application 
of ergonomics'principles in dental clinic; $27^{\text {th }}$ Annual congress of the May 27-28. 2011, Biberach, Germany (poster).

12. Katrova L., Ivanov M., Ivanov I., Shoaib M., Ivchev, M. Assessment of the under-graduate dental students'working postures habits during clinical training. 37th Annual Meeting of the Association for Dental Education in Europe. Antalya, Turkey $7^{\text {th }}-10^{\text {th }}$ September 2011. (poster)

13. Katrova, L. I. Ivanov, M.Ivanov. Readiness and motivation of students and teachers to put into practice ergonomic principles in dental education. Proceedings, of Scientific cession "20 anniversary of the the Department of Dental Public Health, SimelPress, Sofia May 2012. P. 72-79. ISBN: 978-954-2918-61-5

14. Cowpe J. Plasschaert A. Harzer W. Vinkka-Puhakka H. Walmsley AD. Profile and competences for the graduating European dentist - upd 2009. Eur J Dent Educ. 2010 Nov;14(4):193-202. [PubMed] [CrossRef]

15. Belenky, M.M., Rucker, L.M. and Kawamura, Y. "Application of Numeric Terms and Performance Simulation in Dentistry", J. Int. Coll. of
Dent. 17(1):103-116, 1986.

16. Brookhuis, K. A. Hedge, H. Hendrick, E. Salas and N. Stanton. Handbook of Human Factors and Ergonomics Models. Florida: CRC. 2005.

17. Delleman NJ, Haslegrave CM and Chaffin DB Working Postures and Movements. Tools for Evaluation and Engineering. Editors London, New York, Washington: CRC Press LLC, 2004.

18. FDI, Policy Statement, Musculoskeletal Disorders and Dental Practice Adopted by the FDI General Assembly: 26th October 2007, Dubai.

19. Kalheinz Kimmel, Robert Oswald Practising Dentistry, Ergonomic guidelines for the future, Berlin Chicago, Die Quintessenz, 1972.

$20 . \quad h t t p: / / w w w . d e n t a l-$ ergonomics.com/

21. Let ergonomics and true fourhanded dentistry help you Jun 1, 2006 By Betty Ladley Finkbeiner and Michael Muscari.

22. Ergonomics and Disability Support Advisory Committee (EDSAC) to the Council on Dental Practice (CDP). An introduction to ergonomics: risk factors, MSDs, approaches and interventions. American Dental
Association; 2004.

23. Grant KA. Ergonomics: is it optional? PowerPoint presentation.

24. Murphy DC. Ergonomics and the Dental Care Worker. American Public Health Association, United Book Press, Washington, DC;1998.

25. NIOSH. Work-related musculoskeletal disorders. 1997.

26. "Ergonomic requirements for dental equipment" http:// www.optergo.com/i mages/ Ergonomic_req_april2007.pdf [accessed 26 September 2007]

27. "Adopting a sitting working posture during patient treatment" http:/ /www.optergo.com/uk/images/ Adopting.pdf [accessed 26 September 2007]

28. Hamann C, Werner RA, Franzblau A, Rodgers PA, Siew C, Gruninger S. Prevalence of carpal tunnel syndrome and median mononeuropathy among dentists. J Am Dent Assoc. 2001 Feb;132(2):163-170. [PubMed]

29. Werner RA, Hamann C, Franzblau A, Rodgers PA. Prevalence of carpal tunnel syndrome and upper extremity tendinitis among dental hygienists. J Dent Hyg. 2002 Spring;76(2):126-132. [PubMed]

\section{Corresponding author:}

Assoc. Prof. Dr. Lydia Katrova,

Department of Public Dental Health, Faculty of Dental Medicine, Sofia

1, St. Georgi Sofiiski Str,. 1431 Sofia, Bulgaria

Tel: +359/888 569742

E mail: Lydia_katrova@yahoo.com; 